\title{
EN POCAS PALABRAS: SUBJETIVACIÓN Y GRAMATICALIZACIÓN*
}

\author{
EN POCAS PALABRAS: SUBJECTIFICATION AND GRAMATICALIZATION
}

\author{
LAURA BARRoso FERriz \\ Universidad de Alicante \\ 1bf11@alu.ua.es
}

Enviado: 22/05/2019

Aceptado: 03/09/2019

\begin{abstract}
Resumen
El presente análisis pretende dar cuenta del proceso de gramaticalización que ha sufrido la construcción sintáctica "en pocas palabras" a lo largo de la historia del español, desde los orígenes del idioma hasta nuestros días, teniendo en cuenta las dos funciones que podía desempeñar: la de complemento adjunto y la de marcador del discurso. Asimismo, se persigue delimitar cuáles son aquellas características estructurales recurrentes, tanto en los casos en los que esta unidad lingüística funciona como complemento adjunto como en los que desempeña la función de marcador discursivo. Para ello, extraeremos aquellos casos que proporcionan los corpus lingüísticos CORDE y CREA, mediante los cuales fundamentaremos nuestras afirmaciones.

PALABRAS CLAVE: Gramaticalización; subjetivación; marcadores del discurso; marcadores reformuladores; reformulación; recapitulación; "en pocas palabras".
\end{abstract}

\begin{abstract}
This analysis is intended to describe the process of grammaticalization that the syntactic construction "en pocas palabras" has experienced throughout the history of the Spanish language, from its origins to our time, taking into account its two possible functions: adjunct and discursive marker. Moreover, this text intends to establish the limits of those structural characteristics that are recurrent when it is employed in any of its two variants. To achieve this goal, we make use of the text corpus CORDE and CREA to substantiate our findings.

KEYWORDS: Grammaticalization; subjectification; discourse markers; reformulation markers; reformulation; recapitulation; "en pocas palabras".
\end{abstract} * Agradezco a la Universidad de Alicante la ayuda concedida para la realización del presente trabajo gracias a
la beca AII2018-04 del programa propio del VITC para el fomento de I+D+I.

Para citar este artículo / To cite this article: Barroso Ferriz, Laura (2019). En pocas palabras: subjetivación y gramaticalización. ELUA, 33: 27-53. doi: 10.14198/ELUA2019.33.2

Enlace / Link: http://dx.doi.org/10.14198/ELUA2019.33.2 


\section{INTRODUCCIÓN}

El objetivo principal del presente estudio es llevar a cabo un análisis diacrónico del grupo preposicional "en pocas palabras", teniendo en cuenta su evolución histórica hasta que desempeña la función de marcador discursivo. Asimismo, se tendrán en consideración las características formales, o patrones reiterados estructurales, que presentan estos casos ${ }^{1}$.

Así pues, la hipótesis de partida es la siguiente: estimamos que "en pocas palabras", en los inicios de la lengua, desempeñaba la función de complemento adjunto, informando sobre alguna circunstancia del modo en el que se desarrolla la acción. Sin embargo, en un momento determinado, se introdujo esta construcción en un contexto en el que ya no estaba informando del modo en el que se desempeñaba la acción verbal, sino que presentaba una conclusión o recapitulación con respecto a lo dicho anteriormente, es decir, empezó a funcionar, estando vigente todavía el anterior uso, como marcador del discurso.

Para realizar esta investigación, hemos tomado como base de datos tanto el CORDE - Corpus Diacrónico del Español-, como el CREA — Corpus de Referencia del Español Actual-, a partir de los cuales hemos extraído una serie de casos con el fin de obtener un corpus lo suficientemente amplio. Concretamente, hemos extraído un total de 688 casos, tanto escritos como orales, en los que aparece introducido el grupo preposicional "en pocas palabras", 515 del CORDE y 173 del CREA.

A partir de la obtención de dicho corpus, hemos clasificado los casos según funcione la construcción como complemento adjunto o como marcador discursivo, y, de esta forma, evaluaremos el funcionamiento de "en pocas palabras" como marcador discursivo.

\section{CONCEPTOS BÁSICOS}

\subsection{Gramaticalización}

Si bien es cierto que son muchas las denominaciones dadas a este proceso por el cual una unidad adquiere un significado más abstracto (Cifuentes, 2003: 14), debemos la denominación actual a Meillet (1912), quien se interesó en identificar cómo surgen las nuevas categorías y los cambios en el sistema (Traugott, 2010: 271).

Asimismo, los orígenes de este proceso podrían situarse, según Hopper y Traugott (1993), en el siglo XIX, de la mano de grandes estudiosos como Bopp, Humboldt, von der Gabelentz, Schleicher, entre otros. Sin embargo, el estudio actual de los procesos de gramaticalización tiene sus antecedentes en la década de los setenta, momento en que una serie de autores asumió una perspectiva evolutiva y tipológica con el propósito de explicar los diferentes estados sincrónicos de lenguas particulares, tales como, Givón (1979), Hopper y Thomson (1980), Sankof y Brown (1976), etc. (Torres Cacoullos, 2015: 504).

1 El contraste con construcciones aparentemente similares, como en algunas palabras, en escasas palabras, etc., es obvio, por cuanto estas estructuras siempre tienen función sintáctica y, por otro lado, su presencia es mucho menor en los corpus. Por otra parte, la relación con construcciones más problemáticas, como en dos palabras, no constituye objeto de nuestro estudio, pues si bien parece claro que el cuantificador puede haber perdido su valor numeral en ciertos usos, no está claro que ello conlleve de forma obligada la pérdida de función sintáctica. 
Tal y como sucede con la denominación del proceso de gramaticalización, existe una gran cantidad de definiciones dadas sobre el mismo. Sin embargo, podríamos señalar como uno de los aspectos comunes a todas estas propuestas la adquisición, por parte de una unidad lingüística, de un contenido gramatical o más abstracto, o bien el paso de una unidad de contenido gramatical a otro contenido más gramatical. No obstante, es importante destacar que, en términos de Cifuentes (2003: 12), el proceso de gramaticalización no solo ha sido entendido como el paso de un significado léxico a un significado gramatical, o a otro más abstracto, sino que también, y como consecuencia de dicho fenómeno, traerá consigo cambios morfosintácticos y fonológicos.

Sin embargo, cabe señalar que, aunque el modelo tradicional de la gramaticalización implicaba un camino unidireccional hacia la pérdida de propiedades, según los principios expuestos en Lehmann (1995), en estudios posteriores, se propondrá un modelo de pérdida-ganancia y no solo de pérdida (González Manzano, 2007: 20). De esta manera, la ampliación del significado hace posible que una unidad, una vez gramaticalizada, pueda aparecer en contextos que antes no le eran permitidos (2007: 31). Así pues, según Cifuentes (2003: 20-21), hay autores que consideran que no se produce una pérdida del significado léxico en la unidad lingüística, sino que, realmente, se generaliza el significado léxico originario hacia otros ámbitos, o se adquiere un significado distinto al original, pero, de ninguna forma se produce una pérdida o vacío significativo, en todo caso, se produciría un remplazamiento.

Por último, cabría destacar que Company (2015: 516) presenta dos acepciones en cuanto al término gramaticalización. Por un lado, una acepción general y común que significa 'volverse una forma o construcción dadas parte de la gramática de una lengua' y, por otro lado, una acepción especializada, cuyo auge está datado a partir de los años ochenta y en adelante, y que da cuenta de un tipo específico de proceso diacrónico-sincrónico complejo. Asimismo, es importante señalar que esta segunda acepción ha desbancado, casi por completo, a la primera. En esta línea, Company (2015: 516-517) señala que la segunda de las acepciones acuña, a su vez, dos subtipos de gramaticalización. En una primera instancia, nos encontramos con la gramaticalización estándar, también denominada gramaticalización tradicional, la cual se define como el proceso, mediante el cual, las formas léxicas se convierten en formas gramaticales, o las formas que ya son gramaticales se gramaticalizan todavía más. En una segunda instancia, nos encontramos con un segundo tipo de gramaticalización, el cual no recibe ninguna denominación en particular, y consiste en la convencionalización de las estrategias discursivas, esto es, las formas o construcciones que, en un principio, tienen un significado bien pragmático o bien expresivo o discursivo, se convierten en estructuras gramaticales convencionales, carentes de significados discursivos y pragmáticos. En definitiva, ambas definiciones acuñadas por Company suponen un acercamiento al cambio sintáctico de las unidades lingüísticas. En esta línea, la autora (2015: 517) afirma que "la gramaticalización tradicional se centra en el léxico como inicio del cambio y en la morfosintaxis como punto de llegada; [mientras que] la segunda focaliza el discurso y la pragmática como punto de partida y la morfosintaxis como punto de llegada. [Asimismo,] la primera pone énfasis en el estatus categorial inicial y final de la forma que experimenta el cambio, la segunda destaca las motivaciones discursivas que llevan a una forma de entrar en una gramaticalización y en el significado convencional resultante del proceso." 
Consideramos imprescindible señalar que la probabilidad de que se lleve a cabo el proceso de gramaticalización ${ }^{2}$, según Company (2003: 41), dependerá de tres condicionantes, tales como, la ambigüedad, la incorrecta integración paradigmática y la frecuencia de uso. En términos de Llopis Cardona (2018: 79), asimismo, este proceso puede provocar un cambio en la unidad del discurso: de funcionar como una unidad dialógica a funcionar en una unidad monológica. Asimismo, este proceso puede, también, traer consigo un cambio de posición de una unidad monóloga. Por añadidura, Llopis Cardona (2018: 79) considera que también es necesario examinar otros aspectos relevantes, como el contexto que influye en la gramaticalización, los cambios en el significado de cada componente y la motivación para el cambio.

\subsection{Subjetivación}

De esta manera, tal y como afirma Cifuentes (2018: 2), el cambio se producirá desde unidades con significados basados en situaciones extralingüísticas y objetivas, hacia unidades con significados basados en la actitud del hablante sobre aquello que enuncia. Esta implicación progresiva del sujeto de la enunciación en la descripción de una realidad trae consigo una pragmatización del significado, cada vez mayor. Dicho en otras palabras, podemos definir que la subjetivación, en definitiva, no es otra cosa sino un cambio que va de lo que se dice a lo que se quiere decir.

El concepto de subjetivación se ha venido relacionando con los trabajos de Benveniste, quien formuló la distinción entre el sujet d'enoncé y el sujet d'énonciation (González Manzano, 2007: 33). Posteriormente, Traugott (1989: 35) recuperó este concepto y lo definió como "a pragmatic-semantic process whereby meanings become increasingly based in the speaker's subjective belief state/attitude toward the proposition." En palabras de la lingüista, la subjetivación se trataría de un mecanismo pragmático que tiene que ver con el cambio de significado de una serie de elementos, en tanto que pasan de describir una situación objetiva, o una realidad, a describir una situación subjetiva, es decir, situaciones que tengan que ver con la actitud de un hablante sobre el enunciado. Esto se debe a que, con el paso del tiempo, los hablantes generan nuevos significados para los términos que se anclan en lo concreto y los aplican a su experiencia, o, en palabras de Sweetser (1988), "pasan de estar orientados al enunciado a estarlo a la enunciación".

Traugott, por tanto, entiende la noción de subjetivación como un mecanismo semánticopragmático, a través del cual los significados cambian desde la descripción objetiva de la situación externa a la expresión de la perspectiva interna del hablante o la actitud sobre lo que se dice. Según Traugott y Dasher (2002: 97), la subjetivación puede considerarse como el principal tipo de cambio semántico, con lo cual, podría entenderse como un tipo de gramaticalización, entendiendo gramaticalización, tal y como mencionábamos previamente, como la adquisición, por parte de una unidad lingüística, de un contenido gramatical o más abstracto, o bien el paso de una unidad de contenido gramatical a otro contenido más gramatical.

Ahora bien, sin embargo, no todo proceso de subjetivación implicará gramaticalización, ni cualquier tipo de gramaticalización supondrá subjetivación (Traugott, 2010: 38)

2 Refiriéndonos, en este caso, a la gramaticalización en su conjunto y no a la primera ni a la segunda gramaticalización. 
en tanto que no toda gramaticalización supone el mismo grado de subjetivación. Si bien es cierto que Traugott sugirió en un principio (1995: 47) que la subjetivación se daba en los estados iniciales del proceso de gramaticalización, más tarde, ha afirmado (2010: 40) que este proceso suele darse con mayor frecuencia en la gramaticalización primaria ${ }^{3}$ que en la gramaticalización secundaria ${ }^{4}$. Así, podemos admitir que gramaticalización y subjetivación son fenómenos diferentes que pueden darse uno independientemente del otro.

En definitiva, una vez conocemos qué es la gramaticalización y qué es la subjetivación, podemos señalar una fuerte relación entre ambos procesos. En palabras de Brinton y Traugott (2005: 140), since grammaticalization involves shifts toward more abstract, less referential, markers, the prime function of which is to represent the speaker's perspective on the situation or to get others to do things, it is necessarily the case that subjectification is characteristic of grammaticalization. Así pues, la subjetivación es esencial para el desarrollo histórico de los marcadores discursivos.

En esta línea, cabría señalar que Hopper y Traugott (1993: 6) hablan del continuo como uno de los principios fundamentales dentro del proceso de gramaticalización, refiriéndose a que, cuando una unidad lingüística sufre este proceso, la categoría que surge no lo hace de forma inmediata, sino que atraviesa por una serie de etapas, hasta llegar, de forma progresiva, a convertirse en dicha unidad y establecerse, finalmente, como una categoría gramatical dada.

Los continuos o pasos por los que se define y atraviesa el proceso de gramaticalización de una determinada unidad lingüística han sido fijados en dos grandes grupos, uno de naturaleza nominal -de nombre a afijo flexivo-, y el otro verbal -de verbo a afijo flexivo-. Se trata, por su parte, de continuos de descategorización en los que el punto inicial es una categoría plena y el punto final una forma afijal, siendo sus puntos intermedios definidos por una pérdida de las características morfológicas asociadas a la categoría plena (Hopper \& Traugott, 1993: 105). Asimismo, por su parte, Traugott (1996: 1) ha destacado la posibilidad de añadir un tercer continuo de gramaticalización, el cual presentaría el siguiente cambio: «adverbio $>$ adverbio oracional $>$ marcador discursivo», pero, en palabras de Cifuentes (2002: 326) "marcador discursivo no es una categoría gramatical en el sentido tradicional del término, que toma por base su definición oracional, sino que es una categoría discursiva, por lo que su origen puede ser adverbial, pero también el de una categoría plena, como por ejemplo un verbo (oye, mira)". En definitiva, más que plantear un tercer continuo de gramaticalización, podemos considerar la subjetivación como el camino general que puede desarrollar un elemento para funcionar como marcador discursivo, aunque la subjetivación en modo alguno se limite a los marcadores discursivos, sino que abarca muchos más elementos.

En última instancia, y antes de pasar a hablar acerca de los marcadores discursivos reformuladores, cabría dar cuenta de la controversia existente en cuanto al proceso de gramaticalización en los marcadores del discurso.

Según Onodera (2011: 616), parecen existir un total de tres perspectivas acerca de si el desarrollo del marcador del discurso es un caso de gramaticalización. La primera perspectiva lo considera así (Traugott, 1995; Onodera, 1995; Brinton, 1996; Tabor y Traugott, 1998; Suzuki, 1998; Stenström, 1998). Traugott (1995: 1) sostiene que algunos marcadores del discurso, tales como indeed, in fact y besides sí que han sufrido el proceso de gramaticalización.

3 La gramaticalización primaria refiere al cambio que sufren las unidades léxicas al adquirir contenido gramatical.

4 La gramaticalización secundaria refiere al cambio que sufren las unidades gramaticales al adquirir contenido todavía más gramatical. 
Asimismo, la segunda de las perspectivas considera el desarrollo de los marcadores del discurso como un caso de pragmaticalización (Aijmer, 1996; Erman y Kotsinas, 1993), es decir, subjetivación. Así pues, cabría destacar que la pragmática se refiere, en este caso, al proceso por el cual los marcadores del discurso involucran la actitud del hablante hacia el oyente. En esta perspectiva, los elementos pragmáticos se consideran opcionales en la oración, mientras que las formas gramaticalizadas son una parte obligatoria del "núcleo" gramatical (Aijmer, 1996: 3).

Por último, la tercera perspectiva (Barth-Weingarten y Couper-Kuhlen, 2002) considera que los marcadores del discurso no sufren ni gramaticalización ni tampoco pragmaticalización, sino que su propuesta es la siguiente: "tratar la noción de la gramaticalización como una instancia de "prototipicalidad". Esta postura, sin embargo, y siempre en palabras de Onodera (2011: 617) no trae consigo cambios necesarios en términos del análisis de marcadores del discurso. Esta perspectiva nos brinda la ventaja de explicar por qué en determinados casos solo se cumplen algunos de los criterios de gramaticalización tradicionales de Lehmann, así como también nos libera de la necesidad de tomar una decisión binaria en cuanto a si un caso en particular debe contarse como una gramaticalización o no.

\subsection{Marcadores discursivos}

A lo largo de los últimos años, especialmente desde comienzos de los ochenta, están apareciendo contribuciones sobre los llamados "marcadores discursivos" en español actual, sin embargo, esta clasificación no es exclusiva del ámbito hispánico, ya que puede hablarse de que existe una parcela de investigación que se ocupa de elementos análogos a los que mencionamos, en el dominio germánico (Partikelforschung), en el inglés (discourse markers, pragmatic connectives, conjunctive expressions...), en el francés (connecteurs dans le discours), etc. (Martín Zorraquino, 1994: 709)

Según Traugott (2007: 140), estas unidades empezaron a ser estudiadas a partir de la década de los setenta desde diferentes perspectivas. A pesar de ello, determinados autores, tales como Fischer (2006) y Heine (2013), afirman que el estado de los marcadores discursivos continúa siendo incierto. En cualquier caso, definimos marcador discursivo como aquellas unidades lingüísticas normalmente invariables que no ejercen una función sintáctica en el marco de la predicación oracional (Portolés, 2001: 25-26).

Entre las propiedades gramaticales de estos elementos, cabe señalar que, por un lado, facilitan tanto la cohesión textual y la articulación discursiva como la función argumentativa de los encadenamientos entre enunciados o las inferencias que se deducen de los mensajes (Cifuentes, 2007: 1). Asimismo, se caracterizan por la movilidad sintáctica, en tanto que los marcadores presentan más movilidad sintáctica dentro de la oración que las conjunciones. Además de esto, los marcadores podrán ser tanto átonos como tónicos, en este último caso, se situarán entre pausas, de forma que su curva entonativa será distinta con respecto a la unidad superior en que se inserta. Estos elementos, a diferencia de cualquier tipo de complemento, no pueden recibir ningún elemento que lo modifique en tanto que son estructuras fijas. Por esta misma razón, los marcadores no pueden coordinarse entre sí, aunque sí podrán hacerlo con algunos sintagmas que aparecen en inciso. Por añadidura, los marcadores no podrán negarse, pues para ello, antes habría que haberlo afirmado, y para poder afirmarlo sería requisito indispensable el hecho de formar parte de la oración, de esta misma forma tampoco 
podrán ser focalizados, pues no son unidades integradas en la oración, aunque algunos de ellos podrán aparecer habitualmente de forma autónoma en un turno de palabra. Por último, podrán insertarse no solo en oraciones, sino en categorías léxicas y sintagmáticas diversas. (Martín Zorraquino \& Portolés, 1999: 4059-4068)

En términos de Traugott y Dasher (2002: 152), cabe dar cuenta de una serie de marcadores del discurso -tales como "in fact", "after all", "so", "then", "well", "namely", "in other words", etc., que tienen poca semántica conceptual y que no contribuyen significativamente al significado veritativo de las proposiciones, razón por la que algunos investigadores los han considerado un subconjunto de "marcadores pragmáticos" o "partículas metatextuales". Sin embargo, marcan la visión del hablante con respecto al discurso. En este sentido, Schiffrin (1992: 308) demostró que tales marcadores no son carentes de sentido, como se venía considerando, pues, si bien es cierto que sus significados pueden ser algo complicados de entender ${ }^{5}$ son esenciales para la forma de cualquier argumento o narrativa. Por otro lado, no se puede negar que algunos de estos marcadores pragmáticos están restringidos al habla coloquial, sin embargo, muchos se usan en una variedad de tipos de discurso, incluida la prosa expositiva muy alfabetizada.

Asimismo, es innegable que existe una gran cantidad de clasificaciones sobre marcadores discursivos, no obstante, nosotros tomaremos como base la de Martín Zorraquino y Portolés (1999), en tanto que es la más difundida y la que nos resulta más abarcadora y flexible. Atendiendo a dicha clasificación, Martín Zorraquino y Portolés (1999) destacan un total de cinco grupos de marcadores, los cuales presentan a su vez, determinados subtipos, como vemos en la tabla siguiente:

\begin{tabular}{|l|l|l|}
\hline \multicolumn{1}{|c|}{ TIPO } & \multicolumn{1}{|c|}{ SUBTIPO } & \multicolumn{1}{c|}{ EJEMPLO } \\
\hline \multirow{2}{*}{$\begin{array}{l}\text { Estructuradores de la } \\
\text { información }\end{array}$} & Comentadores & Pues, pues bien, así las cosas, etc. \\
\cline { 2 - 3 } & Ordenadores & $\begin{array}{l}\text { En primer/segundo lugar, por una parte/por otra } \\
\text { parte, de un lado/ de otro lado, etc. }\end{array}$ \\
\cline { 2 - 3 } & Digresores & Por cierto, a todo esto, a propósito, etc. \\
\hline Conectores & Conectores aditivos & Además, encima, incluso, etc. \\
\cline { 2 - 3 } & $\begin{array}{l}\text { Conectores consecu- } \\
\text { tivos }\end{array}$ & $\begin{array}{l}\text { Por tanto, por consiguiente, por ende, entonces, } \\
\text { etc. }\end{array}$ \\
\cline { 2 - 3 } & $\begin{array}{l}\text { Conectores contraar- } \\
\text { gumentativos }\end{array}$ & $\begin{array}{l}\text { En cambio, por el contrario, sin embargo, no } \\
\text { obstante, con todo, etc. }\end{array}$ \\
\hline Reformuladores & $\begin{array}{l}\text { Reformuladores ex- } \\
\text { plicativos }\end{array}$ & O sea, es decir, esto es, a saber, etc. \\
\cline { 2 - 3 } & $\begin{array}{l}\text { Reformuladores de } \\
\text { rectificación }\end{array}$ & Mejor dicho, mejor aún, más bien, etc. \\
\hline
\end{tabular}

5 Longacre (1976) los llegó a denominar partículas de misterio. 


\begin{tabular}{|c|c|c|}
\hline TIPO & SUBTIPO & EJEMPLO \\
\hline \multirow[t]{2}{*}{ Reformuladores } & $\begin{array}{l}\text { Reformuladores de } \\
\text { distanciamiento }\end{array}$ & $\begin{array}{l}\text { En cualquier caso, en todo caso, de todos mo- } \\
\text { dos, etc. }\end{array}$ \\
\hline & $\begin{array}{l}\text { Reformuladores reca- } \\
\text { pitulativos }\end{array}$ & $\begin{array}{l}\text { En suma, en conclusión, en definitiva, al fin y } \\
\text { al cabo, etc. }\end{array}$ \\
\hline \multirow{2}{*}{$\begin{array}{l}\text { Operadores argumen- } \\
\text { tativos }\end{array}$} & $\begin{array}{l}\text { Operadores de refuer- } \\
\text { zo argumentativo }\end{array}$ & En realidad, en el fondo, de hecho, etc. \\
\hline & $\begin{array}{l}\text { Operadores de con- } \\
\text { creción }\end{array}$ & Por ejemplo, en particular, etc. \\
\hline \multirow[t]{4}{*}{$\begin{array}{l}\text { Marcadores conversa- } \\
\text { cionales }\end{array}$} & $\begin{array}{l}\text { De modalidad epis- } \\
\text { témica }\end{array}$ & Claro, desde luego, por lo visto, etc. \\
\hline & $\begin{array}{l}\text { De modalidad deón- } \\
\text { tica }\end{array}$ & Bueno, bien, vale, etc. \\
\hline & $\begin{array}{l}\text { Enfocadores de la } \\
\text { alteridad }\end{array}$ & Hombre, mira, oye, etc. \\
\hline & $\begin{array}{l}\text { Metadiscursivos con- } \\
\text { versacionales }\end{array}$ & Bueno, eh, este, etc. \\
\hline
\end{tabular}

\subsubsection{Marcadores discursivos reformuladores}

Entendemos reformulación como un procedimiento de organización del discurso que permite al hablante volver sobre un segmento anterior para reinterpretarlo y presentarlo desde una perspectiva distinta, en palabras de Del Saz (2006: 91) se produce una reformulación entre un segmento discursivo fuente, S1, o cualquiera de sus constituyentes, y el siguiente segmento reformulado, S2, y se señala mediante un marcador de reformulación, que especifica el tipo de relación creada entre los dos segmentos discursivos vinculados.

El hablante, a la hora de reformular, expresa diferentes proposiciones en un enunciado con el fin de satisfacer la necesidad comunicativa del oyente. Así, en la gran mayoría de ocasiones, será el propio hablante quien tenga esta necesidad de reformular, y para ello dispone de varios procedimientos de organización discursiva, como, por ejemplo, la paráfrasis. En esta línea, cabe señalar que, aquello que lleva al locutor a reformular sus ideas son los problemas de comunicación, originados en el propio proceso interactivo (Flores Acuña, 2003: 156), por tanto, las coordenadas que determinan la necesidad de reformular son tanto la intención del hablante como la interpretación del oyente (2003: 159). En definitiva, aquello que caracteriza a la reformulación, en contraste con otras funciones discursivas, es el proceso retroactivo que permite explicar, rectificar, reconsiderar, recapitular o separarse de la formulación anterior (Garcés Gómez, 2008: 69).

Así pues, Corino (2016: 45) propone la idea de que la reformulación "se desencadena por el deseo del hablante de cumplir sus objetivos comunicativos en la negociación del significado y superar, así, cualquier problema comunicativo que pueda surgir en situaciones en las que el 
primero requiera una explicación más detallada. En tal caso, la reformulación previene, señala o incluso puede resolver problemas de malentendidos entre los hablantes, teniendo así un rol funcional-pragmático definido a través de sus funciones metatextuales y metacognitivas".

Rossari (1994) entiende por marcadores de reformulación aquellos "marcadores que presentan el miembro del discurso que introducen como una nueva formulación de un miembro anterior", de esta manera, el hablante considera que lo ya dicho no transmite satisfactoriamente su intención comunicativa y emplea un marcador del grupo de los reformuladores para presentar el miembro del discurso que lo sigue como una mejor expresión de lo que pretendió decir con el miembro precedente.

Tal y como hemos comentado, Martín Zorraquino y Portolés (1999) diferenciaban cuatro subgrupos dentro de los marcadores reformuladores (explicativos, de rectificación, de distanciamiento y recapitulativos). De estos cuatro, nos interesa incidir en los "reformuladores recapitulativos", los cuales permiten al hablante volver sobre la formulación anterior con el fin de extraer de ella aquello que se considera esencial. En este caso, no se pone en cuestión la primera formulación, sino que la segunda parte es el resultado sintético, objetivo o subjetivo, de una visión englobadora de lo expresado en los segmentos anteriores (Garcés Gómez, 2008: 115). En este sentido, el reformulador recapitulativo presenta el miembro del discurso en el que se encuentra como una recapitulación con la misma orientación que los miembros anteriores y acorde con el significado de los nombres que constituyen su origen. Y este será el caso de "en pocas palabras", pues muestra el miembro del discurso que introduce como algo breve, compuesto por pocas palabras.

Según Garrido (2006: 12), para poder explicar satisfactoriamente muchos de los valores de los marcadores discursivos, es necesario acudir al origen y evolución de buena parte de estas partículas. Por lo tanto, se requerirá un análisis integrador, y no meramente sincrónico.

Así, Traugott (1996: 162) entiende que un adverbio puede ser dislocado desde su típica posición interna en la cláusula (dentro del predicado) hacia la posición ocupada por los adverbios de oración. Como estos, evaluará semántica y pragmáticamente el contenido de la proposición. A pesar de su posición sintáctica, continúa Traugott, un sintagma adverbial puede adquirir nuevas funciones pragmáticas y usos polisémicos que potencialmente podrán convertirlo en un marcador discursivo. Con el paso del tiempo, estas funciones pueden semantizarse en esta posición o incluso en otra más dislocada, resultando de ahí la nueva función de marcador discursivo. En esta etapa, concluye, la forma adquirirá nuevas características prosódicas y servirá pragmáticamente para evaluar la relación con los textos precedente y siguiente, y no la proposición en sí misma.

\section{ANÁLISIS HISTÓRICO}

Como expusimos, partimos de los datos extraídos de los corpus académicos CORDE y CREA, -un total de 688 casos, de los cuales 515 son del CORDE y 173 del CREA 6 mediante los cuales fundamentamos nuestras afirmaciones. En este sentido, realizaremos un recorrido histórico de todos los casos de "en pocas palabras" recogidos en los corpus lingüísticos mencionados anteriormente, desde el origen de los escritos del español, con el fin de observar en qué momentos se pierde el valor léxico en favor del valor gramatical.

6 Evidentemente, con los límites que los propios corpus tienen, sean geográficos, textuales o de cualquier otro tipo. 


\subsection{Grupo preposicional en función de complemento adjunto}

Según el Corpus Diacrónico del Español, el grupo preposicional "en pocas palabras" aparece documentado en los escritos, por primera vez, en el año 1250.

(1) E nunca quedava de catar en los libros, e escuchava al que preguntava, e respondíeles en pocas palabras e bien. E en algunas oras de los días andava por los canpos e por los rios, e avía sabor de oír los buenos sones e estar con los disputadores. (Anónimo, Bocados de oro, 1250, CORDE)

Como vemos, el grupo preposicional desempeña la función de complemento adjunto, en tanto que indica una circunstancia semántica del verbo del cual es complemento, responder.

En este caso, a través de la cantidad está dando cuenta de cómo se respondió. Además, el grupo preposicional aparece coordinado al complemento "e bien", hecho por el cual podemos inferir que, si dos complementos se pueden vincular mediante una conjunción copulativa es porque ejercen la misma función sintáctica, de forma que "en pocas palabras" funcionará igual que como "e bien”, es decir, como complemento adjunto.

De igual forma, a partir de los datos extraídos, observamos que la aparición de este grupo preposicional se repite en gran cantidad de ocasiones y que, durante un largo periodo en la historia del idioma, la estructura en cuestión tan solo desarrolla la posición sintáctica de complemento adjunto ${ }^{7}$, denotando alguna circunstancia que tuviera que ver con el verbo principal de la oración.

(2) E Aristótil, segund retrae Plinio, lo uno por aquello que él ende sabié ya d'antes, lo ál por aquello que demandó e aprendió d'aquellos sabidores que Alexandre le envió, fizo de las naturas de las animalias La libros, e dend tomó Plinio esto, e dixo en pocas palabras aquello que nós ende aquí dezimos. (Alfonso X, General Estoria, I parte, 1275, CORDE)

(3) El primero anno del regnado de balthasar Rey de babilonna uio daniel un suenno de suyo yaziendo en so lecho. \& escriuiol en pocas palabras \& diz assi [...] (Alfonso X, General Estoria, IV parte, 1280, CORDE)

(4) Assí que ya era Roboán apartado de la tierra del Rey, su padre, bien cient jornadas y eran ya entrados en otra tierra de otra lengua que no parecía a la suya, de manera que no se podían entender, sino en pocas palabras. (Anónimo, Libro del Cavallero Cifar, 1300 $1305, C O R D E)$

En los ejemplos proporcionados, tal y como se puede apreciar, el grupo preposicional depende sintácticamente del verbo, en tanto que informa de las circunstancias en las que se desarrolla la acción verbal. Sin embargo, no se trata de un complemento exigido por dicho verbo, sino que se caracteriza por su presicindibilidad sintáctica. Por esta razón, dicha estructura desempeñaría, de nuevo, la función de complemento adjunto.

Asimismo, no debemos obviar una serie de rasgos contextuales que podrían resultar pertinentes en el proceso de gramaticalización, estos son, por un lado la presencia (ejemplo 3) y por otro lado la ausencia (ejemplo 4) del discurso referido después de la construcción.

7 Del total de casos que proporcionan los corpus lingüísticos, aquellos que funcionan como complemento adjunto constituyen un $84,77 \%$. 
En esta línea, cabría señalar cuáles son las características estructurales principales que podemos encontrar, de forma reiterada, en los fragmentos extraídos.

Por un lado, destacaríamos la presencia habitual de los dos puntos como signo de puntuación (:), que sigue al grupo preposicional “en pocas palabras”, mediante el cual se está indicando que ha terminado el sentido gramatical, pero no el sentido lógico de la oración, a la vez que se introduce el objeto directo.

(5) E sy dixiere que otro omne la mato o otra bestia la mato o la ljuençio, jure el cauallerizo con vn vezino \& sea creydo, \& peche aquel por quien el cauallerizo jurare. Del curiador de los bueyes, de muchas cosas que son, dezimoslo en pocas palabras: que aquel mesmo fuero aya \& aquel paramjento que el cauallerizo de los cauallos; \& la soldada sea en abenençia de los sennores \& de los boyerizos. (Anónimo, Fuero de Úbeda, 1251-1285, CORDE)

Por otro lado, cabe destacar la dependencia del grupo preposicional con los verbos de dicción o verbos dicendi, que se vincularía con el signo de puntuación mencionado anteriormente, en tanto que designan acciones comunicativas e introducen un parlamento, ya sea en estilo directo o indirecto.

Este tipo de verbos se pueden dividir, por un lado, en verbos de dicción oral, como "decir" -ejemplo 6-, "contar" -ejemplo 7-, etc., y de dicción escrita, como "escribir" -ejemplo 8-. No obstante, también existen casos, aunque menos, en los que la naturaleza de los verbos no es la dicción -ejemplo 9-.

(6) E querémosvos aquí fablar d'ellos de cómo gelos dixo primero por palavra e gelos dio luego de fecho, e primero segund Josefo, porque los dize en pocas palabras, desí como los pone Moisén en la Biblia en el XXo capítulo dell Éxodo e los departen después los santos padres de la nuestra ley e otros que fablaron d'esta razón e dixieron dend más (Alfonso X, General Estoria, I parte, 1275, CORDE)

(7) Ca peró fiziéronlo ellos d'esta guisa, o por fazer entender mejor la estoria e averla más a coraçón los que la oyessen, o por eñader algunas cosas que eran a dezir ý demás d'aquellas que fueran dichas. Onde vos contaremos nós agora aquí esto, peró en pocas palabras, e las pocas palabras serán por razón de la razón doblada. (Alfonso X, General Estoria, I parte, $1275, C O R D E)$

(8) El primero anno del regnado de balthasar Rey de babilonna uio daniel un suenno de suyo yaziendo en so lecho. \& escriuiol en pocas palabras \& diz assi [...] (Alfonso X, General Estoria, IV parte, 1280, CORDE)

(9) Por alma entiendo una sentencia encerrada en una o en dos o en pocas palabras; por cuerpo me agrada designar el mismo símbolo. (Carlos de Sigüenza y Góngora, Teatro y virtudes políticas que constituyen a un príncipe, 1680, CORDE)

Estadísticamente hablando, del total de casos que nos proporcionan los corpus lingüísticos, 584 casos presentan "en pocas palabras" en función de complemento adjunto, de los cuales, un $87,32 \%$ de los casos corresponde a verbos de dicción oral que acompañan al sintagma, mientras que tan solo un 4,79\% de estos pertenecería al total de verbos de dicción escrita. Así, el porcentaje restante, $7,87 \%$, se refiere al total de casos que no presentan verbos de dicción. 


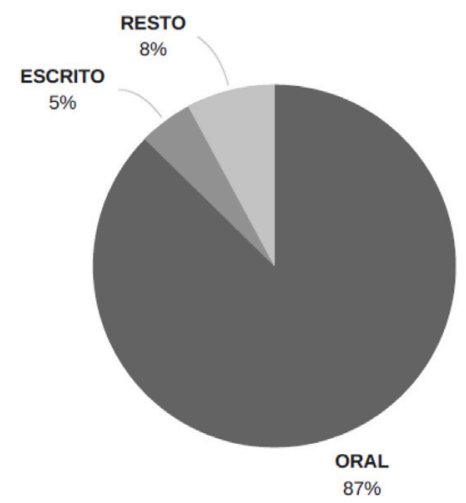

Diagrama 1. Tipología verbal general

Tal y como muestra la siguiente tabla, si realizamos el estudio centrando nuestra atención siglo a siglo, observamos cómo, de nuevo, en todas las épocas el porcentaje mayoritario corresponde con el empleo de verbos de dicción oral.

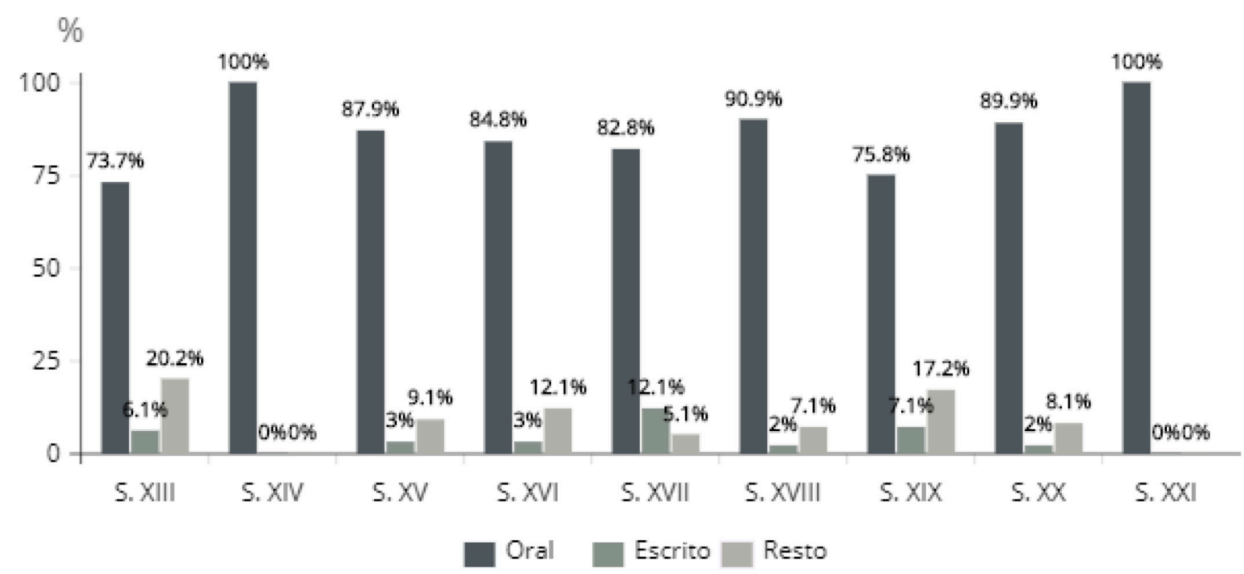

Tabla 1. Tipología verbal cronológica

Por otro lado, podemos clasificar estos verbos desde el punto de vista del emisor, como "preguntar" -ejemplo 10-, "hablar" -ejemplo 11-, etc., y desde el punto de vista del receptor, como "responder" -ejemplo 12-, "entender" -ejemplo 13-, etc.:

(10) Et por que non cunple de dar espaçio nin vagar a esto, dar vos he a entender et responder vos he a las otras cosas que me preguntastes lo mas en pocas palabras que yo pudiere. (Juan Manuel, Libro de los Estados, 1327 - 1332, CORDE) 
(11) E segund dixieron los sabios como quier quel onbre deue fablar en pocas palabras por esso non lo deue fazer en manera que no muestre bien \& abierta mente lo que dixiere (Anónimo, Siete Partidas de Alfonso X. BNM I 766, 1491)

(12) El rrey, despues que oyo las rrazones que Ruy Diaz Cabeça de Vaca le dixo, rrespondio en pocas palabras e dixo * a Ruy Diaz Cabeça de Vaca que don Iohan Alfonso fiziera su voluntad de se tornar e creer las tales cosas, e que fiziera mejor venirsse a la su merçed. (Pero López de Ayala, Crónica del rey don Pedro, 1400, CORDE)

(13) Otrosi los que se trabaian de auer sabiduria de sus enemigos fazen lealtad \& vienen les ende grand pro. \& deuen otrosi mandar a los onbres que vsen fazer ayna las cosas que les mandaren \& que en pocas palabras entiendan lo que les dixieren (Anónimo, Siete Partidas de Alfonso X. BNM I 766, 1491, CORDE)

De nuevo, de los 584 casos, un 78,25\% de los casos corresponde a los verbos que clasificamos desde el punto de vista del emisor, mientras que un $13,86 \%$ se refiere al total de verbos desde el punto de vista del receptor. El porcentaje restante, $7,87 \%$, pertenece al total de casos que no presentan verbos de dicción.

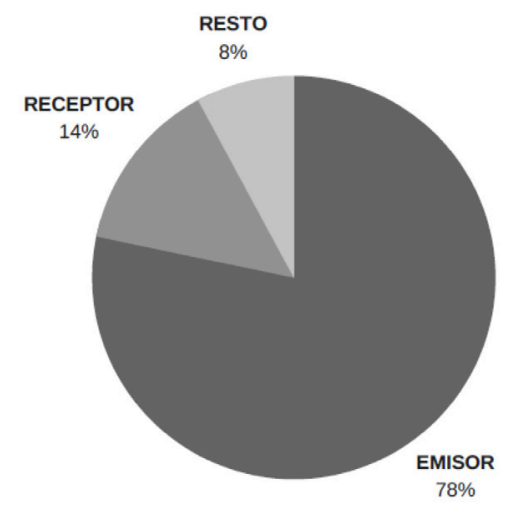

Diagrama 2. Punto de vista E/R general

Asimismo, si exponemos los mismos datos analizados de forma diacrónica, observamos cómo desde el siglo XIII hasta nuestros días, normalmente, predomina el empleo de verbos de dicción desde el punto de vista del emisor. 


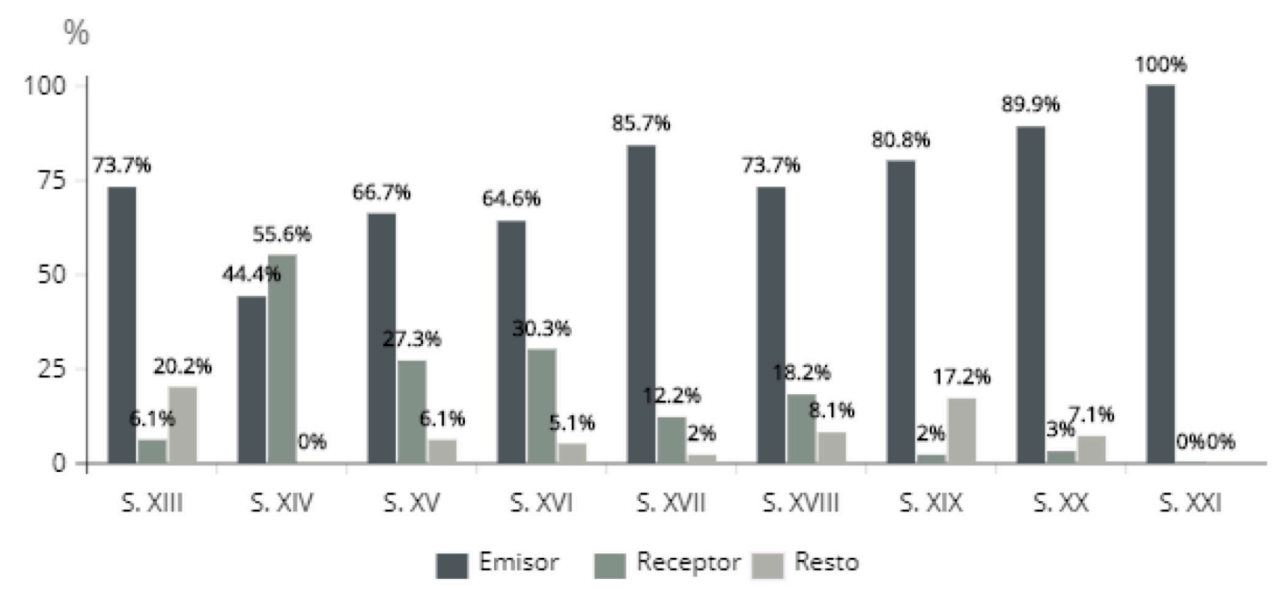

Tabla 2. Punto de vista E/R cronológico

Por añadidura, otra de las características estructurales que podemos encontrarnos es la posición en que la que se ubica el grupo preposicional dentro de una oración. Si bien es cierto que aquello que resulta más habitual es que ocupe la posición pospuesta al verbo, indicando el modo en que se desempeña la acción verbal, encontramos una serie de casos de "en pocas palabras" en posición antepuesta al verbo principal, de forma que sigue indicando una circunstancia del verbo, pero en este caso, de forma enfática o topicalizada:

(14) Asi, en pocas palabras, conto la buena regla e regimiento de la çibdad e el abtoridad e reuerençia de los senadores. (Fernán Pérez de Guzmán, Mar de Historias, 1455, COR$D E)$

En este caso, como podemos observar, se ha producido un cambio en el orden de palabras en tanto que "en pocas palabras" se ha desplazado de su posición habitual, pues, aunque debería ir detrás del verbo, aparece delante de este, razón por la cual aparece entre pausas en el fragmento analizado.

(15) Dime, por Dios ¿cuántas palabras hallas que dijese María virgen en toda la historia de los cuatro evangelios? Entra a ella el ángel, y en pocas palabras, y éstas llenas de santidad y sabiduría, le da razón y le despide. [...] (Juan Justiniano, Instrucción de la mujer cristiana, 1528, CORDE)

De nuevo, nos encontramos con un cambio en el orden de palabras de esta oración, puesto que el grupo preposicional aparece desplazado delante del verbo, además, se introduce una aposición entre dicha estructura y el verbo principal que tiene el objeto de explicar cómo son las palabras con las que el ángel le dio la razón. Es por esto por lo que podríamos afirmar que este caso presenta indicios de su futura conversión en marcador discursivo. 
En este sentido, a la hora de distinguir qué función desempeña "en pocas palabras" dentro del discurso, cabría resaltar que, por lo general, cuando la estructura actúa como complemento adjunto ocupa la posición pospuesta y, por el contrario, cuando desempeña la función de marcador del discurso, aparece en posición antepuesta. Sin embargo, esta no se trata de una regla estricta y, por lo tanto, no determina que si "en pocas palabras" aparece de forma pospuesta deba funcionar como complemento adjunto. En este sentido, para determinar estrictamente qué función desempeña el grupo preposicional, debemos tener en cuenta si dicho grupo indica alguna característica del verbo, es decir, cumple función sintáctica, o si está expresando alguna cuestión relacionada con la actitud del hablante (recapitulación).

Por lo que respecta a la posición que ocupa el grupo preposicional, de los 584 casos en función de complemento adjunto, un 77,39\% corresponde a los casos que aparecen pospuestos al verbo principal, mientras que un $22,60 \%$ pertenece a los casos en los que la estructura está antepuesta al verbo.

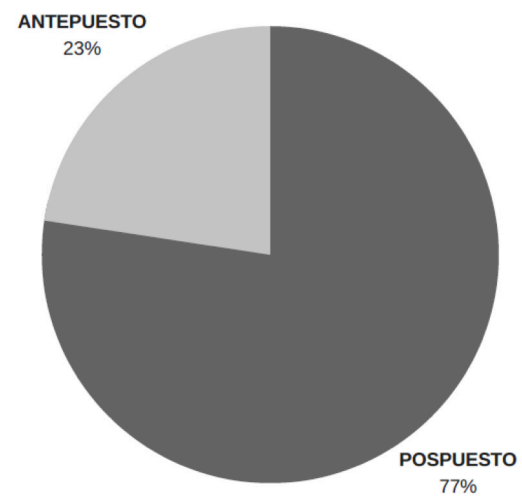

Diagrama 3. Posición general

Si este mismo dato lo analizamos desde una perspectiva histórica, observamos cómo, desde el siglo XIII hasta hoy, la mayor parte de los casos que funcionan como complemento adjunto aparecen pospuestos al verbo principal, habiendo, así, una tendencia clara en la evolución de la frecuencia de uso de cada una de las posiciones.

De igual forma, podemos considerar si el grupo preposicional "en pocas palabras" puede seguir al verbo de forma inmediata -ejemplo 16- o, por el contrario, puede existir un elemento entre el verbo y el grupo preposicional -ejemplo 17-.

(16) El sabio en pocas palabras dize mucho, y dízelas a tiempo. (Alonso de Villegas, Fructus sanctorum y quinta parte del Flossanctorum, 1594, CORDE)

(17) Repíteme pues ahora en pocas palabras la instruccion que acabo de darte. (Juan Francisco de Masdeu, Arte poética fácil, 1801, CORDE) 


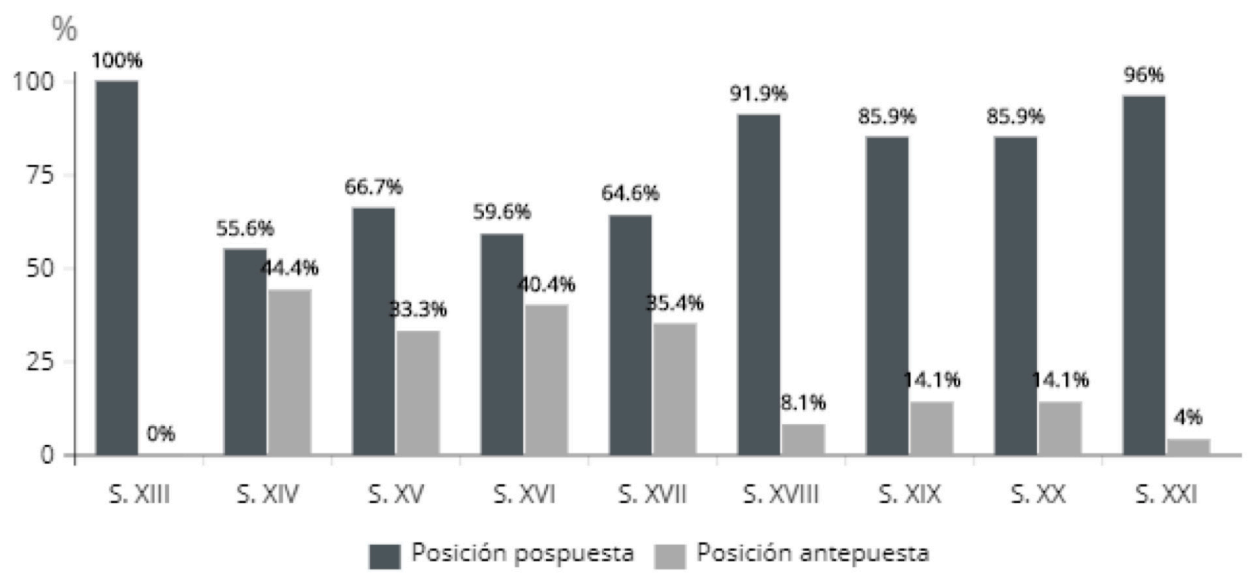

Tabla 3. Posición cronológica

Tal y como podemos apreciar en el diagrama 4, un 76,88\% corresponde a los casos en los que no existe un elemento que separe el complemento del verbo, mientras que el resto, un $23,11 \%$ pertenece a aquellos casos en los que estos dos elementos de la oración no aparecen uno junto al otro.

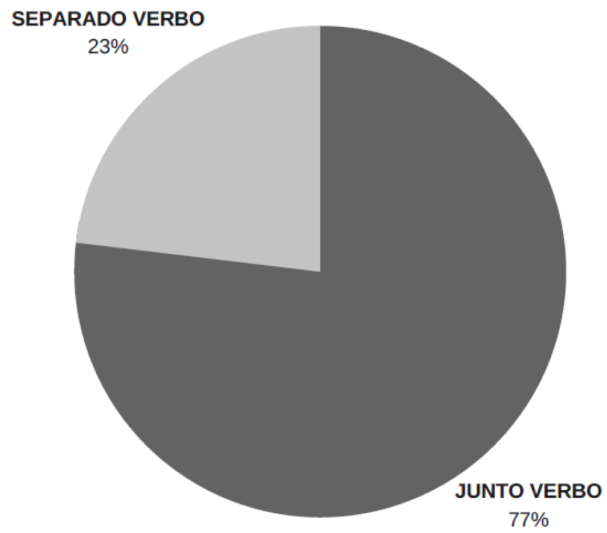

Diagrama 4. Cercanía respecto al verbo general

Desde una perspectiva histórica, como se puede apreciar en la tabla 4, durante un largo periodo de tiempo, desde el siglo XIII, en la mayoría de los casos dicha estructura está ubicada de forma antepuesta o pospuesta al verbo, pero de forma inmediata, es decir, sin ningún elemento entre ambos. De igual forma, no parece haber una discrepancia grande 
entre los siglos, pues salvado el caso del siglo XX, parece haber una proporción muy similar entre los diversos siglos.

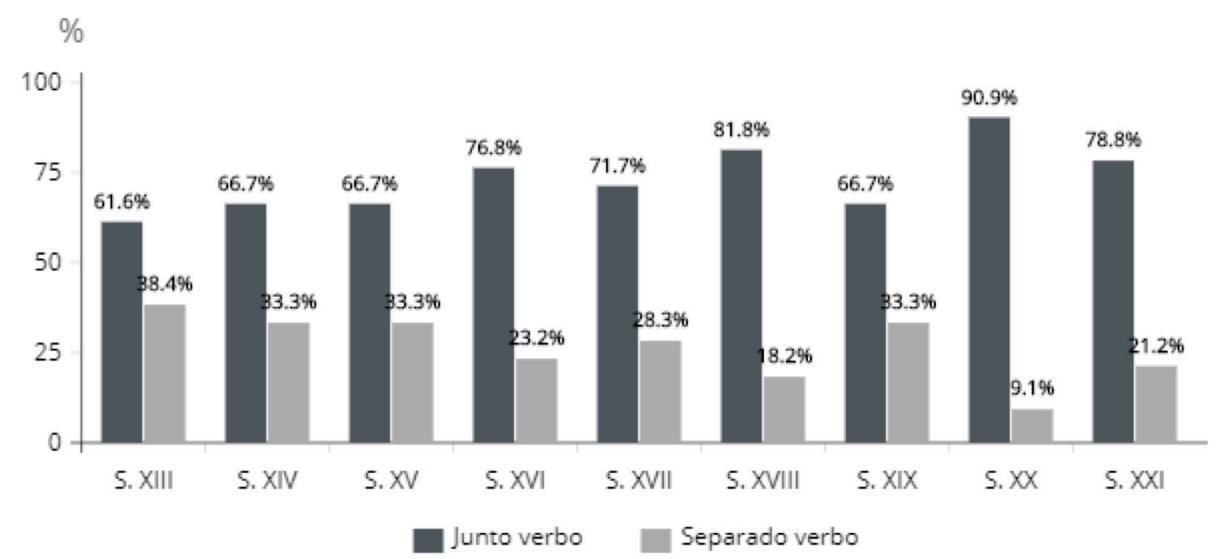

Tabla 4. Cercanía respecto al verbo cronológica

\subsection{Grupo preposicional en función de marcador discursivo}

No será hasta el año 1781 cuando se documente por primera vez el grupo preposicional "en pocas palabras" en función de marcador del discurso.

Cabe afirmar que esta construcción puede funcionar de dos formas diferentes, como complemento del verbo o como marcador del discurso, sin embargo, los primeros funcionamientos como marcador son ocasionales, en tanto que el asentamiento de este uso requerirá tiempo. Estos casos, como veremos, ya no aparecen vinculados a verbos de lengua y entendimiento, como ocurría en los casos comentados anteriormente, sino que indican algo sobre la manera de decir.

(18) Se sabe también que los ciegos hacen caxitas, cestillas, canastillos, y jaulas, y las ciegas hilan y debanan: en pocas palabras: como no quieran holgar, y huir del trabajo, fácilmente hallarán en qué ocuparse. (Juan de Gonzalo Nieto Ibarra, Traducción de Tratado del Socorro de los pobres, de Juan Luis Vives, 1781, CORDE)

En este primer caso, donde la estructura funciona como marcador del discurso, podemos observar cómo, a diferencia de los casos en los que funcionaba como complemento adjunto, ya no depende del verbo sino de la actitud del hablante, en tanto que mediante un verbo de lengua implícito se señala un acto de habla asertivo.

De esta manera, el grupo preposicional ya no presenta subordinación con respecto al verbo principal de la oración, sino que el fin último de esta unidad lingüística es encadenar los diferentes fragmentos del discurso, señalando explícitamente el tipo de relación semántica que existe entre ellos. Así pues, "en pocas palabras" establece una relación semántica de recapitulación entre las diferentes partes del discurso. Por ello, el grupo preposicional, 
en estos casos, no depende del sujeto sintáctico, sino del emisor, en tanto que o bien se explicita o bien se rectifica aquello que pudo ser mal comprendido. Por lo tanto, lo que ocurre en este caso, y en los siguientes en los que la construcción actúa desempeñando la función de partícula marcadora del discurso ${ }^{8}$, es que ha sufrido un proceso de gramaticalización.

En esta línea cabe señalar que, a través de los procesos de gramaticalización y subjetivación, ciertas unidades lingüísticas de uso frecuente son reanalizadas como partículas gramaticales. En nuestro caso, esto es lo que le ha ocurrido al marcador "en pocas palabras", puesto que, basándonos en la consideración de Bosque (1989: 30), la voz afectada deja de estar asociada a conceptos o ideas que poseen un contenido léxico, como ocurría cuando el grupo preposicional funcionaba como complemento adjunto, y, una vez ha perdido su significado conceptual, pasa a expresar un significado gramatical, de modo que acaba desempeñando determinadas funciones sintácticas que consisten, fundamentalmente, en estructurar el contenido proposicional de la oración o del texto del que forman parte. De esta manera, las voces gramaticalizadas se convierten en piezas fundamentales para la construcción del texto, tanto en el plano oracional como en el discursivo. Con lo cual, podríamos afirmar que en los casos en los que actúa como marcador discursivo, la construcción se encuentra completamente gramaticalizada, en tanto que, aunque cambie el contexto, la estructura no varía, pues no se puede alterar el orden de sus elementos ni introducir nada entre ellos, sino que suele presentarse como unidad fija e independiente entre pausas.

De esta forma, el grupo preposicional deja de depender sintácticamente del verbo y, por lo tanto, ya no indicaría una circunstancia referida a este, tal y como ocurría en los casos en los que funcionaba como adjunto, sino que, cuando desempeña la función de marcador del discurso, el hablante retoma una idea mencionada previamente para reinterpretarla y presentarla de forma distinta, pudiendo explicar, rectificar, reconsiderar o recapitular la formulación anterior.

En cualquier caso, basándonos en los casos que nos facilitan los corpus lingüísticos, no será hasta el año 1852 cuando documentamos el siguiente caso de "en pocas palabras" funcionando como marcador discursivo.

(19) Pero, ¿qué es el tornillo de Arquímedes? Preguntaron algunos concurrentes. -No es muy fácil explicarlo: es, acabando en pocas palabras, la jeringa con que Inglaterra administra los clisterios á la Europa. (José Somoza, El árbol de la charanga, 1852, CORDE)

En este fragmento encontramos, de nuevo, la estructura en cuestión actuando como marcador del discurso en tanto que explica o recapitula, en este caso, qué es el tornillo de Arquímedes.

Es importante destacar que, durante los primeros siglos de los escritos del español, se observa una carencia del grupo preposicional "en pocas palabras" desempeñando la función de fórmula marcadora del discurso, pues, como podemos comprobar, si bien es cierto que la primera vez que se recoge el grupo preposicional "en pocas palabras" en los escritos es a mitad del siglo XIII, no será hasta finales del siglo XVIII cuando nos encontremos este sintagma gramaticalizado por primera vez. Asimismo, como hemos reflejado anteriormente, hasta mediados del siglo XIX no se volverá a recoger el segundo caso de

8 Del total de casos que proporcionan los corpus lingüísticos, aquellos que funcionan como marcador discursivo constituyen un $15,12 \%$. 
"en pocas palabras" como marcador del discurso. El hecho de que exista un largo periodo de tiempo entre un caso y otro, probablemente, se deba a que cuando aparece "en pocas palabras" como marcador del discurso por primera vez, no se asienta inmediatamente en la sociedad como tal, sino que requiere un proceso de adaptación mediante el cual los hablantes terminen asumiendo esta función de "en pocas palabras" como recapitulador de lo dicho previamente. Es decir, la extensión y convencionalización de uso parece que fue lenta.

No obstante, podemos observar cómo, a partir de este segundo caso del grupo preposicional como marcador discursivo, cada vez se hace más patente el empleo de estas unidades lingüísticas invariables, cuyo significado está fijado y condiciona el procesamiento del discurso. En palabras de Portolés (2001: 25-26), no ejercen una función sintáctica en el marco de la predicación oracional y poseen un cometido coincidente en el discurso: el de guiar, de acuerdo con sus distintas propiedades morfosintácticas, semánticas y pragmáticas, las inferencias que se realizan en la comunicación.

Como comentábamos, a medida que avanzamos en el tiempo esta construcción aparece con mayor frecuencia funcionando como marcador. Esta afirmación la corroboramos mediante el siguiente ejemplo, que, como vemos, está datado pocos años después del anteriormente mencionado.

(20) Aquella ligera entrevista dejaba en su ánimo una profunda y desconocida emoción, una tristeza indefinible que borraba de su memoria la imagen del pobre provinciano, tímido y mal vestido, para ceder su lugar al joven modesto y sentimental, que en pocas palabras, dejaba entrever un corazón de grandes sensaciones. (Alberto Blest Gana, Martín Rivas. Novela de costumbres político-sociales, $1862-1875$, CORDE)

Así pues, podríamos afirmar que a partir del momento en que el elemento gramaticalizado empieza a asentarse en la sociedad, este elemento podría interpretarse bien como complemento adjunto o bien como fórmula marcadora del discurso, es decir, los dos usos conviven, pues el surgimiento de un nuevo valor más gramatical no elimina el significado original, debiendo considerar el continuo de gramaticalización, por tanto, como un proceso de superposición y coexistencia. En el paso de una categoría a otra existe siempre un estadio intermedio donde coexisten las dos estructuras, solapándose conceptual y morfosintácticamente sus respectivas propiedades en determinados contextos, en una estructura como la siguiente: A > A, B > B (Heine, Claudi \& Hünnemeyer, 1991a: 223, 1991b: $165-166)^{9}$.

Esta idea la vemos reflejada en una misma obra, Manual de higiene privada (1881) en la que aparece un caso de "en pocas palabras" como marcador -ejemplo 21- y otro caso en el que funciona como complemento adjunto -ejemplo 22-.

(21) Agréguense á estos desórdenes funestos los que alcanzan á la economía en general; pérdida del apetito, digestiones laboriosas, palpitaciones, aneurismas, rotura de vasos sanguíneos, demacracion, impotencia, esterilidad, palidez del rostro, debilitacion de

9 Este proceso de solapamiento y coexistencia ha recibido el nombre de dualidad (Heine \& Reh, 1984: 57), principio de divergencia (Hopper, 1991: 24), retención (Bybee \& Pagliuca, 1987: 112; Ziegeler, 1997; Torres Cacoullos, 2000: 4-6; Salminen, 2002), o cadena de gramaticalización (Heine, 1992: 349; Heine, Claudi \& Hünnemeyer, 1991a: 171, 1991b: 53). 
la vista, obtusion del oido, perversion en los demas sentidos externos, tísis pulmonar, pérdida de la memoria, deterioracion del juicio, idiotismo adquirido, manía, espasmos, temblores, convulsiones, catalepsia, epilepsia, enfermedad de Pott: tales son, en pocas palabras, los amargos frutos de los excesos en la satisfacción de la necesidad instintiva que nos ocupa. (Tomás Orduña Rodríguez, Manual de higiene privada, 1881, CORDE).

(22) Los medios que la química tiene para reconocer estos fraudes, y expongamos en pocas palabras las enfermedades que estas adulteraciones producirán. (Tomás Orduña Rodríguez, Manual de higiene privada, 1881, CORDE).

Con esto, observamos cómo los hablantes empiezan a asumir este uso del elemento en cuestión, mediante el cual, en palabras de Martín Zorraquino y Portolés (1999: 4121-4122), si el hablante consideraba que lo dicho no transmitía satisfactoriamente su intención comunicativa, empleaba la estructura "en pocas palabras" con el fin de presentar un miembro del discurso introducido como una reformulación que aclara, o explica, aquello que se ha querido decir en el miembro anterior y que era poco comprensible.

Asimismo, un hecho que convendría señalar en cuanto a la frecuencia de uso es que, tras el análisis de casos documentados por el Corpus del Español Actual -CREA-, hemos observado que se recogen un total de cincuenta y cuatro fragmentos de prensa en los que aparece el grupo preposicional "en pocas palabras", y, curiosamente, en la mayoría de ellos el grupo preposicional desempeña la función de marcador del discurso:

(23) Se trataba, en pocas palabras, de crear la impresión y apariencia de democracia. (Prensa, El País, 1977. CREA)

(24) Se trataba, en pocas palabras, de recuperar a Brasil de los últimos vestigios del régimen impuesto en el golpe de 1964, hace 20 años. (Prensa, Revista Hoy, 1984. CREA)

(25) Resumiendo, en pocas palabras podemos decir que sólo quedan tres países comunitarios a la cola de la política social: España, Portugal y Grecia. (Prensa, El País, 1988. CREA)

(26) Eso es, en pocas palabras, el SSC de Delco Electronics, una división de Delphi Automotive Systems. (Prensa, El Mundo, 1996. CREA)

Esto se explicaría, muy probablemente, porque, a pesar de que la prensa sea un género escrito, se caracteriza fundamentalmente por su carácter comunicativo, en tanto que el lenguaje periodístico se vale de gran cantidad de aspectos propios de la oralidad. Asimismo, también influye de forma importante que el uso de "en pocas palabras" como marcador que expresa recapitulación está totalmente asumida por la sociedad en el momento en los que se recogen los ejemplos expuestos. 
Retomando la idea que exponíamos anteriormente de que los marcadores del discurso pueden darse de forma más frecuente en la conversación oral, cabe señalar que el Corpus del Español Actual expone una serie de casos transcritos de conversaciones orales y espontáneas de principios del siglo XXI. En la gran mayoría de estos casos, como veremos, el grupo preposicional "en pocas palabras" funciona como marcador del discurso:

(27) No sé, porque yo me gusta mucho la Historia y eso en ese sentido, ¿no? O sea, me encantaría así, qué sé yo, todo lo que leí en los libros ir y ver, ¿verdad?, en pocas palabras. (Oral, CREA)

(28) Ya sé que es una animalada, pero en pocas palabras, señor Cebrián, ¿si tuviera usted que definir esta estos diez años que quedan atrás y que usted vivió desde un puesto privilegiado, al menos en la historia de España, cómo lo haría? (Oral, CREA)

Tal y como hemos comentado anteriormente, cabría indicar algunas de las características estructurales que suelen darse en los casos en los que "en pocas palabras" funciona como marcador discursivo.

En una primera instancia, debemos como uno de los rasgos más importantes el hecho de que el grupo preposicional ya no dependa de ningún verbo, sino de la comunicación en general.

(29) De este trabajo debe ocuparse otro profesor preparando a los discípulos para que el de piano pueda, en pocas palabras, aplicar los conocimientos ya adquiridos por el alumno en las obras que con él estudie prácticamente. (Manuel de Falla, Escritos sobre música y músicos, 1916 - 1939, CORDE)

(30) Es, en pocas palabras, un escándalo. (Marcos Aguinis, La cruz invertida, 1970, CORDE)

Por añadidura, también podemos encontrar casos en los que la construcción ocupa la posición antepuesta -ejemplo 31- y casos en los que ocupe la posición pospuesta a la explicación dada -ejemplo 32-

(31) En una misma línea encontramos el tema del consumo; en pocas palabras es el propio hombre el que se está dañando a sí mismo por poner el peligro el planeta. (Efímero, Examen escrito 1992, 1992, CREA)

(32) Encontramos un punto más de cercanía entre Bley y Zappa: ambos optan por manejarse, encontrar ellos sus alternativas, vender su producto, no su creatividad. Tener el control, en pocas palabras. (Alain Derbez, Los usos de la radio, 1988, CREA)

Tal y como se observa en el diagrama 5, en la mayoría de casos donde "en pocas palabras" funciona como marcador discursivo, la estructura aparece en posición antepuesta a la reformulación dada. 


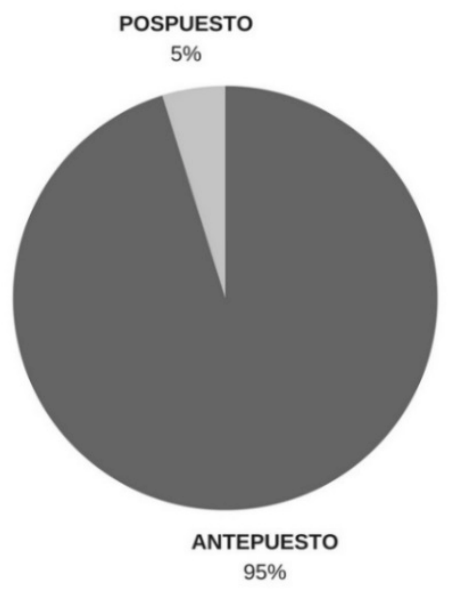

Diagrama 5. Posición general

Teniendo en cuenta que el primer caso de "en pocas palabras" funcionando como fórmula marcadora del discurso aparece en el siglo XVIII, realizaremos el mismo estudio de forma diacrónica a partir de este momento. Si nos detenemos en la siguiente tabla, observamos cómo en el siglo XVIII el 100\% de los casos corresponde al grupo preposicional en posición antepuesta, no obstante, es importante tener en cuenta que durante este siglo se documenta un único caso. Sin embargo, tal y como hemos observado en el diagrama sectorial anterior, la mayoría de los casos ocupan la posición antepuesta con respecto a lo reformulado.

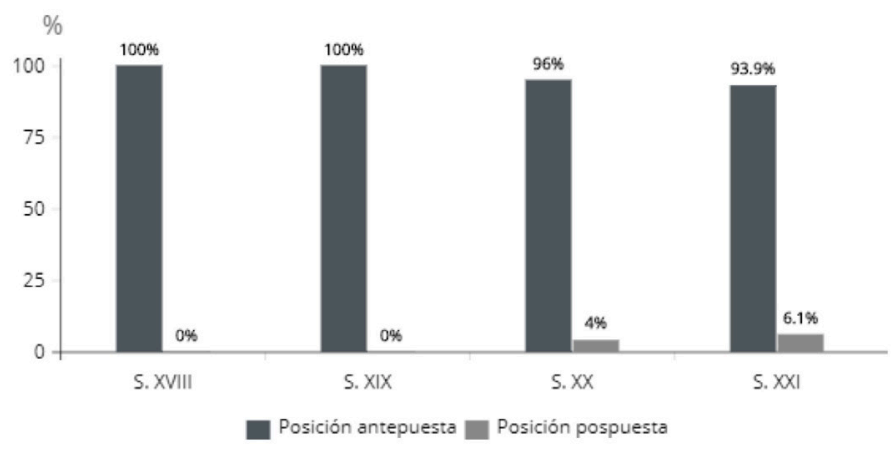

Tabla 5. Posición cronológica

Siguiendo con la posición que ocupa la estructura en la oración, cabe señalar que "en pocas palabras" puede aparecer entre comas -ejemplo 33-, seguido de dos puntos explicativos -ejemplo 34- o, por el contrario, inmediatamente antes o después del verbo, sin ningún signo de puntuación -ejemplo 35-. 
(33) El procedimiento ó sistema, Boucherie, para la inyección de las maderas con el sulfato de cobre, es, en pocas palabras, el siguiente: [...] (José Martín y Santiago, Material telegráfico de línea, 1888, CORDE)

(34) Llevas contigo los planos topográficos y una tabla indicadora del tiempo: en pocas palabras: el área designada, el Área $\mathrm{H}$, se extiende desde las pendientes nor-occidentales del Moncayo hacia el Guadarrama, Gredos y la sierra Cabrera. (Juan Goytisolo, Reivindicación del conde don Julián, 1970, CORDE)

(35) En una misma línea encontramos el tema del consumo; en pocas palabras es el propio hombre el que se está dañando a sí mismo por poner el peligro el planeta. (Efímero, Examen escrito 1992, 1992, CREA)

Tal y como observamos en el siguiente diagrama, del 100\% de los casos en los que el grupo preposicional desempeña la función de fórmula marcadora del discurso, un $84,61 \%$ corresponde a aquellos casos en los que la construcción aparece entre comas, mientras que un $6,73 \%$ pertenece a los fragmentos en los que se documenta el grupo preposicional seguido de dos puntos explicativos, en tanto que este signo de puntuación sirve para enunciar aquello que se pretende reformular. Y, por último, el resto de casos, un $8^{\prime} 65 \%$, corresponde a aquellos en los que ocupa una posición en el fragmento -antepuesta o pospuesta- pero sin ningún signo de puntuación.

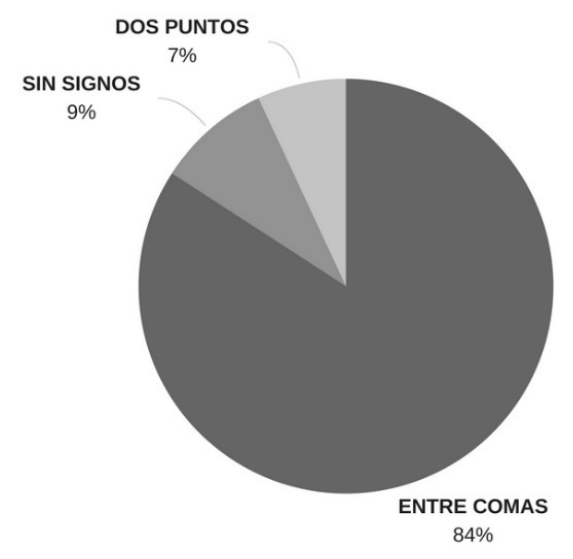

Diagrama 6. Elementos gráficos general

Si lo analizamos de forma segmentada, observamos lo siguiente: en el siglo XVIII, como ya sabemos, aparece un $100 \%$ debido a que tan solo se documenta un caso ${ }^{10}$, así, a excepción de esto, durante el resto de siglos nos damos cuenta de que la gran mayoría de casos corresponde con aquellos que se posicionan en la oración entre comas ${ }^{11}$.

10 Es realmente importante tener en cuenta que el CORDE presenta una serie de carencias con respecto a la lengua del periodo histórico que abarca del siglo XVIII a la primera mitad del XIX.

11 Hay que tener en cuenta a este respecto no ya que el uso de los signos de puntuación ha variado a lo largo de los siglos, sino que la labor de puntuación depende en muchas ocasiones del editor, lo que pueda dar lugar a diversas interpretaciones al respecto. 


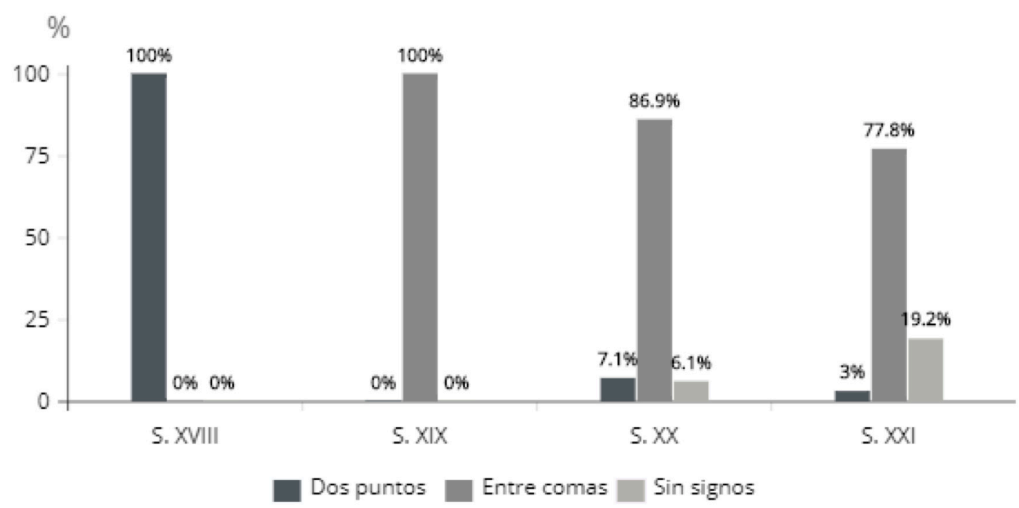

Tabla 6. Elementos gráficos cronológico

En definitiva, cabría señalar que cuando el grupo preposicional "en pocas palabras" desempeña la función de marcador, se encuentra completamente gramaticalizado, por lo que no varía su forma, aunque cambie el contexto, así como tampoco se puede alterar el orden de sus elementos ni introducir nada entre ellos, sino que se presenta como una unidad independiente, y como hemos visto, normalmente entre pausas.

Con el fin de cerrar el análisis, exponemos a continuación una tabla que resume los casos documentados de en pocas palabras en los corpus lingüísticos, CREA y CORDE, a partir del siglo XIII hasta nuestros días, $\mathrm{y}$, a su vez, dentro del total de casos en cada siglo, cuántos desempeñan la función de complemento adjunto o, por el contrario, cuántos la función de marcador del discurso.

\begin{tabular}{|l|c|c|c|c|c|}
\hline \multirow{2}{*}{} & \multicolumn{2}{|c|}{ Complemento adjunto } & \multicolumn{2}{c|}{ Marcador del discurso } & Total \\
\cline { 2 - 6 } & $\mathbf{N}$ & $\mathbf{\%}$ & $\mathbf{N}$ & $\%$ & \\
\hline S. XIII & 15 & $100 \%$ & 0 & $0 \%$ & 15 \\
\hline S. XIV & 9 & $100 \%$ & 0 & $0 \%$ & 9 \\
\hline S. XV & 33 & $100 \%$ & 0 & $0 \%$ & 33 \\
\hline S. XVI & 150 & $100 \%$ & 0 & $0 \%$ & 150 \\
\hline S. XVII & 39 & $100 \%$ & 0 & $0 \%$ & 39 \\
\hline S. XVIII & 37 & $97,36 \%$ & 1 & $2,63 \%$ & 38 \\
\hline S. XIX & 102 & $98,07 \%$ & 2 & $1,92 \%$ & 104 \\
\hline S. XX & 175 & $71,72 \%$ & 69 & $28,27 \%$ & 244 \\
\hline S. XXI & 24 & $42,85 \%$ & 32 & $57,14 \%$ & 56 \\
\hline
\end{tabular}

Tabla 7. Evolución cronológica de los casos 
Debido a que durante el siglo XX aumenta notablemente el número de casos en función de marcador discursivo, pasaremos a dar los datos por periodos de 25 años:

\begin{tabular}{|l|c|c|c|c|c|}
\hline \multirow{2}{*}{} & \multicolumn{2}{|c|}{ Complemento adjunto } & \multicolumn{2}{c|}{ Marcador del discurso } & \multicolumn{2}{c|}{ Total } \\
\cline { 2 - 6 } & $\mathbf{N}$ & $\mathbf{\%}$ & $\mathbf{N}$ & $\mathbf{\%}$ & \\
\hline S. XX & $\mathbf{1 7 5}$ & $\mathbf{7 1 , 7 2 \%}$ & $\mathbf{6 9}$ & $\mathbf{2 8 , 2 7 \%}$ & $\mathbf{2 4 4}$ \\
\hline $1900-1925$ & 50 & $90,90 \%$ & 5 & $9,09 \%$ & 55 \\
\hline $1925-1950$ & 29 & $80,55 \%$ & 7 & $19,44 \%$ & 36 \\
\hline $1950-1975$ & 24 & $72,72 \%$ & 9 & $27,27 \%$ & 33 \\
\hline $1975-2000$ & 72 & $60 \%$ & 48 & $40 \%$ & 120 \\
\hline
\end{tabular}

Tabla 8. Evolución cronológica de los casos del siglo XX

\section{CONCLUSIONES}

Tal y como avanzábamos al comienzo de este estudio, el propósito de este trabajo era analizar de forma diacrónica la construcción "en pocas palabras" con el fin de dar cuenta de la evolución que ha sufrido hasta desempeñar la función de marcador discursivo. Así pues, a partir de los casos estudiados y expuestos anteriormente, hemos podido extraer una serie de conclusiones que plantearemos a continuación.

A raíz del análisis de casos, cabría destacar que, en una primera instancia, nos encontramos la construcción "en pocas palabras" desempeñando la función de complemento adjunto, con una serie de características estructurales recurrentes, tales como la presencia del signo de puntuación “:”, la dependencia de los verbos dicendi -orales o escritos ${ }^{12}$ y desde el punto de vista del emisor o del receptor ${ }^{13}$-, la posición que ocupa -pospuesta o antepuesta ${ }^{14}$ - y la aparición -o no- de un elemento que separe la estructura del verbo ${ }^{15}$, las cuales las hemos explicado en profundidad en el capítulo anterior. Sin embargo, a partir de un determinado momento (siglo XVIII), este grupo preposicional adquiere un nuevo valor de fórmula marcadora del discurso. Es en este momento cuando dicha unidad ya no depende del verbo principal, sino de la actitud que muestra el hablante, así, esta progresiva participación del sujeto hablante conlleva un cambio en la unidad que va de lo que se dice a aquello que se quiere decir. En este caso, también hemos dado cuenta de las características más recurrentes, tales como la posición que ocupa el sintagma, en función de marcador, -antepuesta o pospuesta ${ }^{16}$ - y la forma que tiene de aparecer en la oración en que se inserta, -dos puntos, entre comas o sin ningún signo de puntuación ${ }^{17}$-.

$125 \%$ escrito, $87 \%$ oral y $8 \%$ restantes.

$1314 \%$ receptor, $78 \%$ emisor y $8 \%$ restantes.

$1477 \%$ pospuesto y $23 \%$ antepuesto.

$1523 \%$ separado del verbo y $77 \%$ junto al verbo.

$165 \%$ pospuesto y $95 \%$ antepuesto.

$177 \%$ dos puntos, $84 \%$ entre comas y $8 \%$ sin signo de puntuación. 
Teniendo en cuenta lo anteriormente expuesto, cabe destacar que, como venimos afirmando, este grupo preposicional experimenta un proceso de subjetivación, en la medida en que no pretende describir la realidad objetiva, sino expresar la perspectiva interna del hablante, pues no depende de la estructura sintáctica oracional, sino del acto de habla aseverativo implicado.

Por todo lo anterior, observamos cómo nuestra hipótesis de partida ha sido corroborada, en tanto que hemos demostrado cómo dicha unidad lingüística, durante los primeros siglos de los escritos del español, desempeñaba la función de complemento adjunto, y que, sin embargo, en un determinado momento, esta unidad adquirió un nuevo valor que conviviría con el ya existente. En este segundo uso, la construcción no pretende informar del modo en el que se desempeña una acción verbal, sino que presenta una conclusión o recapitulación con respecto a lo dicho anteriormente. En realidad, se trata de un modificador del valor aseverativo del acto de habla dado, de ahí la estrecha vinculación con estructuras comunicativas.

\section{REFERENCIAS BIBLIOGRÁFICAS}

AIJMER, K. (1996). Conversational Routines in English: Convention and Creativity. London: Longman. BRINTON, L. J. \& E. C. TRAUGOTT. (2005). Lexicalization and Language Change. Cambridge: Cambridge University Press.

CIFUENTES, J. L. (2002) "Sobre la gramaticalización preposicional de los adverbios en -mente", En In Memoriam Manuel Alvar (1923-2001), Zaragoza: Institución "Fernando el Católico", pp. 325-339.

CIFUENTES, J. L. (2003). “La gramaticalización”. En Locuciones prepositivas. Sobre la gramaticalización preposicional en español. Alicante: Universidad de Alicante Servicio de Publicaciones, pp. 11-57.

CIFUENTES, J. L. (2007). "Marcadores discursivos". Liceus, Servicios de Gestión y Comunicación: https://aprende.liceus.com/producto/marcadores-discursivos/ (07/03/2019)

CIFUENTES, J. L. (2018). Construcciones con clítico femenino lexicalizado. Madrid: Verbum.

COMPANY COMPANY, C. (2003). "La gramaticalización en la historia del español”. En Medievalia, $n^{\circ} 35$, pp. 3-61.

COMPANY COMPANY, C. (2015). "Continuidades y discontinuidades en la periodización sintáctica del español. La evidencia del siglo XVII”. En Actas del IX Congreso Internacional de Historia de la Lengua Española, Cádiz.

CORINO, E. (2016). "Learners and reformulative discourse markers. A case study of the use of cioè by students of Italian as a foreign language". En Language, Interaction and Acquisition, pp. 44-66.

DEL SAZ, M. M. (2006). "An Overview of Spanish discourse markers of reformulation". En Odisea, $\mathrm{n}^{\circ} 7$, Almería, pp. 89-101.

FANEGO, T. (2010). "Paths in the development of elaborative discourse markers: Evidence from Spanish". En Subjectification, Intersubjectification and Grammaticalization, Kristin Davidse, Lieven Vandelanotte \& Hubert Cuyckens (Eds.), Berlín: De Mouton Gruyter, pp. 197-237.

FISCHER, K. (2006). Approaches to discourse particles (Studies in pragmatics 1). Bingley, UK: Emerald Group Publishing.

FLORES ACUÑA, E. (2003). Los marcadores de refomulación: análisis, aplicado a la traducción español/ italiano de "en fin" y "de hecho". Málaga: Universidad de Málaga Servicio de Publicaciones y Divulgación Científica.

GARCÉS GÓMEZ, M. P. (2008). La organización del discurso: marcadores de ordenación y de reformulación, Frankfurt am Main: Iberoamericana Vervuert.

GARRIDO, M. C. (2006). "Gramaticalización y marcadores del discurso: los contraargumentativos", Estudios humanísticos. Filología, nº 28, pp. 9-26. 
GONZÁLEZ MANZANO, M. (2007). Gramaticalización de los marcadores epistémicos en español, Barcelona,: Publicacions i Edicions de la Universitat de Barcelona

HEINE, B. (2013). "On discourse markers: Grammaticalization, pragmaticalization, or something else?". En Linguistics, volume 51 (6), pp. 1205-1247.

HOPPER, P. \& E. C. TRAUGOTT. (1993). Grammaticalization. Cambridge: Cambridge University Press.

KURYŁOWICZ, J. (1975). "The evolution of gramatical categories”, en J. K., Esquisses linguistiques, vol. II. Munich: Wilhelm Fink, pp. 38-54.

LEHMANN, C. (1995). Thoughts on Grammaticalization, Múnich: Lincom Europa.

LÓPEZ-COUSO M. J. (2010). "Subjectification and intersubjectification". En Historical Pragmatics. Volumen 8, Andreas H. Jucker e Irma Taavitsainen (Eds.), Berlín: De Gruyter Mouton, pp. 128-162.

LLOPIS CARDONA, A. (2018). "The historical route of eso si as a Contrastive Connective". En Beyond Grammaticalization and Discourse Markers, New Issues in the Study of Language Change, Salvador Pons Bordería y Óscar Loureda Lamas (Eds.), Leiden, Boston: Brill Publishers, pp. 78-114.

MARTÍN ZORRAQUINO, M. A., \& J. PORTOLÉS LÁZARO. (1999). "Los marcadores del discurso". En Gramática descriptiva de la lengua española. Volumen III "Cuarta parte. Entre la oración y el discurso". Ignacio Bosque y Violeta Demonte (Coords.). Real Academia Española, Madrid, Espasa, pp. 4051-4214.

NARROG, H., \& B. HEINE. (2011). "Introduction". En The Oxford Handbook of Grammaticalization. Heiko Narrog y Bernard Heine (Eds.). Oxford: Oxford University Press, pp. 1-10.

ONODERA, N. (2011). "The Grammaticalization of Discourse Markers". En The Oxford Handbook of Grammaticalization, Heiko Narrog y Bernd Heine (Eds.). Oxford: Oxford University Press, pp. 615-654.

PORTOLÉS, J. (2001). “La pragmática y los marcadores". En Marcadores del discurso. Barcelona: Ariel Letras, pp. 25-26.

SCHIFFRIN, D. (1992). El análisis de la conversación. Panorama de la lingüistica moderna de la Universidad de Cambridge, Tomo IV. Madrid: Visor Distribuciones.

SWEETSER, E. (1988). "Grammaticalization and semantic bleaching". En Proceedings of the fourtgeenth anual meeting of the Berkeley linguistics society, Berkeley, California: Berkeley Linguistics Society.

TORRES CACOULLOS, R. (2015). “Gramaticalización”. En Enciclopedia de Lingüística Hispánica, Javier Gutiérrez Rexach (Coord.), Reino Unido: Routledge, pp. 504-514.

TRAUGOTT, E. C. (1989). "On the rise of Epistemic Meanings in English: An Example of Subjectification in Semantic change". En Language 65 (1), pp. 31-35.

TRAUGOTT, E. C. (1995). "The role of the development of discourse markers in a theory of grammaticalization". En Conferencia presentada en la ICHL XII, Standford: Standford University Press, pp. 1-16.

TRAUGOTT, E. C. (1996). "Grammaticalization and Lexicalization”. En Concise Encyclopedia of Sintactic Theories, Oxford: Pergamon.

TRAUGOTT, E. C., \& DASHER, R. B. (2002). “The framework”. En Regularity in semantic change, Cambridge: Cambridge University Press, pp. 1-50.

TRAUGOTT, E. C., \& DASHER, R. B. (2002). "The development of adverbials with discourse markers function". En Regularity in semantic change, Cambridge: Cambridge University Press, pp. 152-187.

TRAUGOTT, E. C. (2007). "Discussion article: discourse markers, modal particles, and contrastive analysis, synchronic and diachronic". En Catalan Journal of Linguistics, $\mathrm{n}^{\circ}$ 6, pp. 139-157.

TRAUGOTT, E. C. (2010). "Grammaticalization". En Continuum Compation to Historical Linguistics, Silvia Luraghi y Vit Bubenik (Eds.), New York: Continuum International Publishing Group, pp. 269-283. 
